\title{
Recent advances in the drug treatment of heart failure
}

\author{
Finlay A McAlister, Koon K Teo
}

\begin{abstract}
Summary
A number of important questions surrounding the treatment of systolic congestive heart failure have been answered by randomised clinical trials completed within the past 2 years. In particular, these studies have established that high-dose angiotensin-converting enzyme (ACE) inhibition is more beneficial than low dose therapy, and that angiotensin II receptor antagonists are an acceptable alternative in patients unable to tolerate ACE inhibitors. Digoxin has been shown to be the only inotropic agent not associated with increased mortality, while amiodarone exerts a modest survival benefit in arrhythmiaprone patients. Beta-blockers appear to be beneficial for selected patients although their precise role remains to be defined by ongoing studies.
\end{abstract}

Keywords: heart failure; ACE inhibitors; angiotensin II receptor antagonists; digoxin; beta-blockers; anti-arrhythmics

Division of General Internal Medicine, Ottawa Civic Hospital, Ottawa, Ontario, Canada

F A McAlister

Division of Cardiology, University of Alberta Hospital, Alberta, Canada K K Teo

Correspondence to Dr F McAlister, Centre for Evidence-Based Medicine, Level 5, The Oxford Radcliffe NHS Trust, Headington, Oxford $\mathrm{OX}_{3}$ 9DU, UK

Accepted 8 July 1998
Recent therapeutic advances in the management of congestive heart failure (CHF) on the basis of systolic dysfunction are reflected in the large number of studies on CHF published or presented at meetings in the last two years. While some therapies previously thought to be promising have been shown to be efficacious, others are associated with adverse outcomes, and new therapeutic options have emerged which hold significant potential for the future.

\section{Angiotensin-converting enzyme (ACE) inhibitors}

While numerous clinical trials ${ }^{1}$ have clearly established that ACE inhibitors reduce morbidity and mortality and are the agents of first-choice in the treatment of systolic CHF (for both symptomatic and asymptomatic patients), ${ }^{2}$ the optimal dose has only recently been clarified by the Assessment of Treatment with Lisinopril and Survival (ATLAS) trial. In this randomised, double-blind trial, the effects of low-dose (2.5-5 mg daily) lisinopril were compared to highdose (32.5-35 mg daily) lisinopril in 3164 symptomatic patients with systolic CHF (M Packer, American College of Cardiology 47th Annual Scientific Session, Atlanta, GA, 1998). While both doses were equally well-tolerated, those patients treated with high-dose lisinopril had markedly fewer hospitalisations for $\mathrm{CHF}$ (odds ratio $(\mathrm{OR}) 0.76, \mathrm{p}=0.002$ ) and less all-cause mortality or all-cause hospitalisations (OR 0.88, $\mathrm{p}=0.002$ ). These findings are consistent with other smaller studies, ${ }^{34}$ and support the contention that ACE inhibitor dosage should be maximised in patients with CHF.

\section{Angiotensin II (A-II) receptor antagonists}

Unlike ACE inhibitors, the A-II receptor antagonists block the actions of angiotensin II without increasing bradykinin levels. The recently published Evaluation of Losartan in the Elderly (ELITE) study, ${ }^{5}$ a randomised comparison of losartan against captopril in 722 symptomatic elderly CHF patients with poor left ventricular function, confirmed that the A-II receptor antagonist losartan had similar actions to the ACE inhibitor captopril (as measured by symptom scores and functional class), but was better tolerated. However, this study also reported a survival benefit with losartan over captopril $(4.8 \%$ vs $8.7 \%$ mortality, $46 \%$ relative risk reduction, $\mathrm{p}=0.035$ ). A similarly unexpected survival benefit with losartan was observed in two short-term exercise studies ${ }^{6}$ in 736 patients with NYHA Class II-IV failure and left ventricular ejection fraction $\leqslant 40 \%$. Although promising, these data reflect only a small number of endpoints (49 deaths in the ELITE study in contrast to over 1300 in the ACE inhibitor trials ${ }^{1}$ ) and suggest the need for further studies (such as the ongoing ELITE-II trial, a long-term mortality study comparing losartan with captopril).

\section{Digoxin}

The role of digitalis in CHF patients with sinus rhythm has been investigated in the Digoxin Investigation Group (DIG) trial, which did not demonstrate a beneficial reduction in all-cause mortality from digoxin but suggested that digoxin can reduce the number of hospitalisations for $\mathrm{CHF}$ and improve the quality of life in these patients. ${ }^{7}$ That digoxin is the only inotropic agent which has not been shown to increase the risk of death is also encouraging. Subgroup analyses ${ }^{8}$ suggested that those patients with lower ejection fractions, larger hearts, severe symptoms (NYHA Class III and IV), and non-ischaemic aetiologies appeared to benefit most from digoxin therapy, although symptomatic improvement was also gained by those patients with predominantly diastolic dysfunction. 


\section{Other inotropes}

The past few months have not seen encouraging results in studies of inotropic agents other than digoxin. Increased mortality rates with treatment were reported in recent studies of dopamine agonists, such as ibopamine, and sodium pump inhibitors with mild phosphodiesterase activity, such as vesnarinone, similar to and consistent with the adverse effects seen with beta-agonists and phosphodiesterase inhibitors. The Second Prospective Randomised Study of Ibopamine on Mortality and Efficacy (PRIME II), ${ }^{9}$ a randomised trial of ibopamine versus placebo in 1906 patients with advanced CHF treated with ACE inhibitors, was stopped early due to a significantly increased risk of death in subjects allocated to ibopamine therapy ( $25 \%$ vs $20 \%$ in the placebo arm, $\mathrm{p}=0.02)$. Similarly, the Vesnarinone Trial (VEST), a randomised, placebocontrolled trial of vesnarinone in 3833 NYHA Class III or IV CHF patients, the majority of whom were taking ACE inhibitors, reported a dose-dependent increase in mortality with vesnarinone: the relative risk of mortality was $112 \%$ in those subjects receiving $30 \mathrm{mg} /$ day and $123 \%$ in those allocated $60 \mathrm{mg} /$ day (J Cohn, American Heart Association 69th Meeting, New Orleans, 1996). We would agree with Drs Niebauer and Coats that "it may be time for a moratorium on human studies that investigate stimulatory drugs of the catecholamine receptor and their post-receptor pathways until convincing animal data show chronic survival benefit". ${ }^{10}$

\section{Beta-blockers}

Despite the strong physiologic rationale supporting the use of beta-blockers in $\mathrm{CHF}^{2}$ the clinical trial results have been largely disappointing until recently. In the past year, five trials of carvedilol, a non-selective beta-blocker with novel ancillary properties, have reported impressive reductions in mortality and hospitalisations (but, interestingly, no improvement in exercise tolerance) in patients with stable CHF. The US Carvedilol Heart Failure Group ${ }^{11}$ randomised 1094 NYHA Class II-IV CHF patients, most of whom also received an ACE inhibitor, diuretic, and digoxin, in four separate but related trials. After median follow-up of 6.5 months, all-cause mortality in the carvedilol-treated patients was reduced by $65 \%(7.8 \%$ vs $3.2 \%, \mathrm{p}<0.001)$ and hospitalisation for cardiovascular causes by $27 \%(19.6 \%$ vs $14.1 \%, \mathrm{p}=0.036)$. The Australia/New Zealand study ${ }^{12}$ was also a placebo-controlled trial of carvedilol in 415 NYHA Class I or II CHF patients stabilised on conventional therapy (85\% on ACE inhibitor, $75 \%$ diuretics). After a mean follow-up of 19 months, there was no significant difference in mortality risk between the groups $(9.6 \%$ vs $12.6 \%$, $\mathrm{p}>0.1$ ), but a $26 \%$ relative risk reduction was seen in the combined endpoint of death or hospitalisation ( $63 \%$ in the placebo group vs $50 \%$ in the carvedilol group, $\mathrm{p}=0.02$ ).

The enthusiasm for these impressive results should be tempered with some caution. Firstly, the primary endpoints in these studies were exercise tolerance or hospitalisation rates, not mortality, and the reported survival benefits should be regarded with caution given the small number of deaths in each trial. Secondly, all five trials, using an open-label run-in period prior to randomisation, excluded

Table Recent important trials in congestive heart failure

\begin{tabular}{|c|c|c|c|}
\hline Trial & Study drug & Patients & Results \\
\hline ATLAS & $\begin{array}{l}\text { low dose vs high dose } \\
\text { lisinopril }\end{array}$ & $\begin{array}{l}n=3164, \text { LVEF }<30 \%, \text { NYHA class II to IV } \\
\text { symptoms }\end{array}$ & $\begin{array}{l}24 \% \text { reduction in CHF hospitalisations } \\
\text { in high dose group }\end{array}$ \\
\hline ELITE & losartan vs captopril & $\begin{array}{l}n=722, \text { age } \geqslant 65 \text { yrs, LVEF }<40 \%, \text { NYHA class II to } \\
\text { IV symptoms }\end{array}$ & $\begin{array}{l}46 \% \text { reduction in mortality in losartan } \\
\text { group }\end{array}$ \\
\hline DIG & digoxin vs placebo & $n=6800, \mathrm{LVEF}<45 \%$, normal sinus rhythm & $\begin{array}{l}\text { no difference in mortality; } 28 \% \\
\text { reduction in hospitalisations for CHF in } \\
\text { digoxin group }\end{array}$ \\
\hline PRIME II & ibopamine $v s$ placebo & $\begin{array}{l}n=1906, \mathrm{LVEF}<35 \%, \text { NYHA class III or IV } \\
\text { symptoms }\end{array}$ & $\begin{array}{l}26 \% \text { increase in mortality in ibopamine } \\
\text { group }\end{array}$ \\
\hline VEST & vesnarinone vs placebo & $n=3833$, NYHA class III or IV symptoms & $\begin{array}{l}12 \% \text { increase in mortality in low-dose } \\
\text { vesnarinone group, } 23 \% \text { increase in } \\
\text { mortality in high-dose vesnarinone } \\
\text { group }\end{array}$ \\
\hline $\begin{array}{l}\text { US Carvedilol Heart Failure } \\
\text { Group }\end{array}$ & carvedilol vs placebo & $n=1094, \mathrm{LVEF}<35 \%$ & $\begin{array}{l}65 \% \text { reduction in mortality in carvedilol } \\
\text { group }\end{array}$ \\
\hline $\begin{array}{l}\text { Australia/New Zealand Heart } \\
\text { Failure Group }\end{array}$ & carvedilol vs placebo & $n=415, \mathrm{LVEF}<45 \%$, NYHA class II or III & $\begin{array}{l}26 \% \text { reduction in death or } \\
\text { hospitalisation in carvedilol group }\end{array}$ \\
\hline SWORD & d-sotalol vs placebo & $n=3121, \mathrm{MI}$ survivors with $\mathrm{LVEF}<40 \%$ & $\begin{array}{l}65 \% \text { increase in mortality in sotalol } \\
\text { group }\end{array}$ \\
\hline
\end{tabular}

Trial citations and full titles are in the text. $\mathrm{LVEF}=$ left ventricular ejection fraction, NYHA $=$ New York Heart Association, $\mathrm{MI}=$ myocardial infarction. 


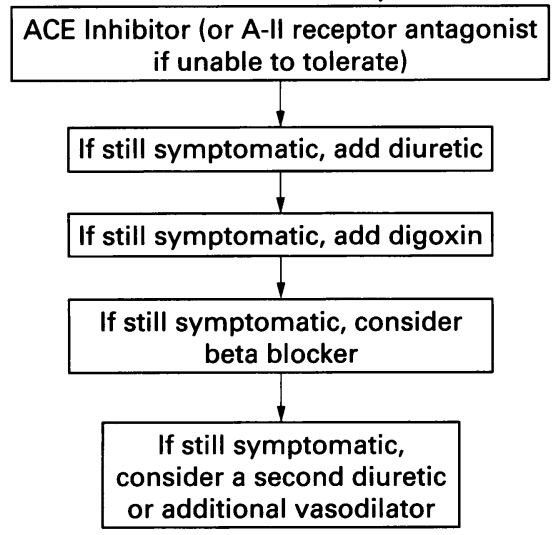

Figure Algorithm for the drug treatment of patients with CHF on the basis of systolic dysfunction patients who did not tolerate the drug. Thirdly, although carvedilol was associated with significant improvements in left ventricular ejection fraction, none of the trials demonstrated an improvement in exercise capacity. In fact, there was a trend towards worsening symptoms in the carvedilol-treated patients over the first 6 months in the Australia/New Zealand Trial. Finally, the population enrolled in these trials (mean age 60 years, $41 \%$ non-ischaemic aetiology, only $2 \%$ NYHA Class IV) may not accurately reflect the CHF population in the community, ${ }^{13}$ who tend to be older, sicker, and have a higher proportion of ischaemic cardiomyopathy.

A recent meta-analysis ${ }^{14}$ of 24 randomised beta-blocker trials ( 3141 patients, average follow-up 13 months) reported a $31 \%$ reduction in odds of death in those subjects assigned to beta-blocker therapy (annual mortality rates $9.7 \%$ vs $7.5 \%, p=0.004)$. However, the carvedilol trials contributed over half of the patients in this analysis and the conclusions were based on only 297 deaths in the 24 trials (contrast this with ACE inhibitors whose efficacy was established from experience with over 1300 deaths"). Thus the "results are still not definitive... large scale, long-term randomized trials of beta-blockers in patients with heart failure are now required to confirm the benefits suggested by this overview". ${ }^{14}$ Such trials are underway (BEST and CIBIS-II) and a recommendation for routine beta-blockade therapy in $\mathrm{CHF}$ awaits more conclusive results.

\section{Anti-arrhythmic therapy}

Amiodarone continues to hold promise for the treatment of ventricular arrhythmias in CHF patients. A recent meta-analysis of the anti-arrhythmic trials ${ }^{15}$ found that amiodarone was safe in high-risk patients and was associated with a statistically significant (though modest) reduction in mortality in patients with heart failure (OR $0.79,95 \%$ confidence interval $0.64-0.99, \mathrm{p}=0.03$ ). However, this conclusion is based on only 1431 patients and, as the effect estimates in small meta-analyses can differ markedly from those subsequently established in large, definitive randomised trials, ${ }^{16}$ further studies are required to define the precise role of amiodarone in the treatment of $\mathrm{CHF}$.

Sotalol is often used as an anti-arrhythmic agent. The premature termination of the SWORD study, ${ }^{17}$ a placebo-controlled clinical trial of d-sotalol in 3121 patients with left ventricular systolic dysfunction and recent or remote myocardial infarction, due to excess mortality in the d-sotalol group (5\% vs $3.1 \%$ in the placebo group, $p=0.006$ ), has raised concerns about the use of sotalol in CHF patients. Until further evidence is available, d-sotalol does not have a place in patients with compromised left ventricular function, particularly if there is a history of ischaemic heart disease.

\section{Conclusions}

ACE inhibitors should still be considered the drugs of first choice in heart failure, although losartan would appear to be an acceptable alternative in those patients unable to tolerate ACE inhibition due to bradykinin-mediated effects such as intractable cough or angioedema. Diuretics and digoxin remain routine therapies for symptom relief. Amiodarone appears to be safe for the treatment of symptomatic arrhythmias in heart failure. Beta-blockers, in particular carvedilol, hold significant promise, although their precise role remains to be defined. Preliminary evidence ${ }^{18}$ suggests that comprehensive heart failure clinics, staffed by physicians, nurses, and pharmacists who specialise in heart failure management and provide intensive out-patient support, may be associated with improved clinical outcomes. As such, a multidisciplinary approach to these often complicated patients should be supported.

Both authors were supported by the Alberta Heritage Foundation for Medical Research; Dr McAlister was also supported by the Medical Research Council of Canada.
1 Garg R, Yusuf S, for the Collaborative Group on ACE Inhibitor Trials. Overview of randomised trials of angiotensin-converting enzyme inhibitors on mortality and morbidity in patients with heart failure. $\mathcal{F} A M A 1995 ; 273: 1450-6$.

2 McAlister FA, Teo KK. The management of congestive heart failure. Postgrad Med $\mathcal{f} 1997$; 73:194-200.

3 Forster RE, Johnson DB, Barilla F, et al. Effect of low versus titrated dose of ramipril on left ventricular remodelling in patients after $\mathrm{Q}$-wave myocardial infarction with asymptomatic left ventricular dysfunction. Circulation 1996;95: 1189.
4 Pacher R, Stanek B, Globits S, et al. Effects of two different enalapril dosages on clinical, haemodynamic and neurohumoral response of patients with severe congestive heart failure. Eur Heart ₹ 1996;17:1223-32.

5 Pitt B, Segal R, Martinez FA, et al for the ELITE Study Investigators. Randomised trial of losartan versus captopril in patients over 65 with losartan versus captopril in patients over 65 with heart failure (Evaluation of Losartan in the Eld-

6 Klinger G, Jaramillo N, Ikram H, et al. Effects of losartan on exercise capacity, morbidity and mortality in patients with symptomatic heart failure.[abstract] $₹ \mathrm{Am}$ Coll Cardiol 1997; 29(suppl A):205A.
7 The Digitalis Investigation Group. The effect of digoxin on mortality and morbidity in patients with heart failure. N Engl f Med 1997;336:52533.

8 Yusuf S, Garg R, Smith T, et al. Which heart failure patients benefit the most from long term digoxin therapy? $\mathcal{A}$ Am Coll Cardiol 1997; (suppl I):I-23.

9 Hampton JR, van Veldhuisen DJ, Kleber FX, e al for the Second Prospective Randomized Study of Ibopamine on Mortality and Efficacy Study of Ibopamine on Mortality and Efficacy
(PRIME II) Investigators. Randomised study of (PRIME II) Investigators. Randomised study of advanced severe heart failure. Lancet 1997;349: 971-7. 
10 Niebauer J, Coats AJS. Treating chronic heart failure: time to take stock. Lancet 1997;349: failure:

11 Packer M, Bristow MR, Cohn JN, et al for the Packer M, Bristow MR, Cohn JN, et al for the
US Carvedilol Heart Failure Study Group. $N$ Engl f Med 1996;334:1349-55.

12 Australia/New Zealand Heart Failure Research Collaborative Group. Randomised, placebocontrolled trial of carvedilol in patients with congestive heart failure due to ischemic heart disease. Lancet 1997;349:375-80.

13 Parmeshwar J, Shackell MM, Richardson A Poole-Wilson PA, Sutton GC. Prevalence of heart failure in three general practices in north west London. Br ₹ Gen Pract 1992;42:287-9.

14 Doughty RN, Rodgers A, Sharpe N, MacMahon S. Effects of beta-blocker therapy on mortality in patients with heart failure. A systematic overview of randomized controlled trials. Eur Heart 7 1997; 18:560-5.

15 McAlister FA, Teo KK. Antiarrhythmic therapies for the prevention of sudden cardiac death Drugs 1997;54:235-52.

16 Borzak S, Ridker PM. Discordance between meta-analyses and large-scale randomized, con- trolled trials. Examples from the management of acute myocardial infarction. Ann Intern Med 1995;123:873-7.

17 Waldo AL, Camm AJ, de Ruyter H, et al. Effect of d-sotalol on mortality in patients with left ventricular dysfunction after recent and remote myocardial infarction. Lancet 1996;348:7-12.

18 Fonarow GC, Stevenson LW, Walden JA, et al. Impact of a comprehensive heart failure management program on hospital readmission and functional status of patients with advanced heart failure. F Am Coll Cardiol 1997;30:725-32.

\section{Medical Anniversary \\ JEAN-MARTIN CHARCOT, 29 November 1825}

Jean-Martin Charcot (1825-93) was born in Paris, France, the second son of a carriage-maker. He trained in Paris and became a physician at the Salpêtrière Hospital. There are several disorders which Charcot was the first to describe and these are known as Charcot's diseases. They include intermittent claudication (1856), lead poisoning (1864), amyotrophic lateral sclerosis and multiple sclerosis (1865), and tabetic arthropathy (1869). He died of pulmonary oedema and angina due to aortic incompetence in August 1893.

Axel Munthe described Charcot as short of stature, with the chest of an athlete and the neck of a bull, a white clean-shaven face, a low forehead, cold penetrating eyes, an aquiline nose, sensitive lips and the mask of a Roman emperor. His brilliant Friday morning case demonstrations were acclaimed internationally.

In August 1881 the seventh International Medical Congress was held in London. Charcot discussed neuropathic joint disease and localisation of function in the cerebral cortex. In the main hall of the congress there were busts of Pasteur, Virchow, and Charcot, and at the final dinner in the Crystal Palace the night sky was lit with firework portraits of Paget and Charcot. $-D$ G fames 